\title{
HERBAL SUPPLEMENTS - ISSUES RELATED TO THEIR USE
}

\author{
K. Sokolova*, Zh. Tsokeva \\ Department of Pharmacology and Clinical Pharmacology, Faculty of Medicine, Trакіa University, \\ Stara Zagora, Bulgaria
}

\begin{abstract}
The growing need of dietary supplements, self- medication and patients' non-disclosure of herbal supplements use to doctors, the possible occurrence of adverse effects and the interaction with prescribed and over the counter drugs are among the reasons that require more rigorous assessment of the usefulness and safety of herbal supplements in order to best integrate them into common regimens. Lax control of production and distribution, and the lack of uniform legislation determine the need for changes in the regulation and harmonization of legislation in this area. Developing an appropriate postmarketing quality, efficacy and safety surveillance program will be a useful step, allowing the generation of important and relevant information for optimizing the risk - benefit ratio.
\end{abstract}

Key words: products, natural origin, risk, disclosure, pharmacovigilance

\section{INTRODUCTION}

Globally, there is a growing interest and use of products of natural origin, most of which are available as dietary supplements (DS). $(1,2)$ US market of DS exceeds 30 billion dollars annually in 2012, which is $7.5 \%$ growth compared to 2011.

(3http://www.fasebj.org/content/28/1_Supple ment/809.1 - aff-2) The researches identify the most frequent used supplement are multivitamins and minerals, omega-3 fatty acids, plant-based supplements. $(4,5)$

Definitions for DS are similar in different countries. According to the Dietary Supplements Health and Education Act - 1994 (DSHEA) dietary supplement is a product other than tobacco, which is taken orally, intended to supplement the diet and contains one of the following components of the diet: vitamin, mineral, herb or other plant amino-acid food substance intended to supplement the diet by increasing the daily intake of nutrients or a

\footnotetext{
*Correspondence to: Kameliya Sokolova, Department of Pharmacology and Clinical Pharmacology, Faculty of Medicine, Trakia University, Stara Zagora, Bulgaria, Armeiska 11 St., 6000 Stara Zagora, Bulgaria, Tel.: +35942664310, E-mai address: camel56@abv.bg
}

concentrate, metabolite, component or a combination of said ingredients (6) According to European definition given by the European Union (EU) Directive on Food Supplements (2002/46/EC) "Food supplement" means food stuff the purpose of which is to supplement the normal diet and which are concentrated sources of vitamins, minerals or other substances with a nutritional or physiological effect, alone or in combination, marketed in dose form, namely form as capsules, pastilles, tablets, pills and other similar forms, sachets of powder, ampoules of liquids and powders designed to be taken in measured small unit quantities. (7)

The United States has the longest experience in monitoring of the use of DS. The most often cited source of data concerning levels of use DS are NHANES. $(4,8)$ A pooled analysis of data from different series NHANES shows a steady upward trend in the use since 1971 and holding stable at around 50\% since 2000. Due to methodological features, these data reflect the intake of DS mainly among regular users. An inclusion of occasional and seasonal users of supplements reflects in increased frequency of use of $64-65 \%$ of adult Americans. (5)

In Europe an exagereted use of DC also is reported, although researches on their use has 
not done so regularly, as in America and most studies are at national level. (9-13) Information on the use of DS at European level are limited and it is difficult to make correct conclusions due to differences in methodology of individual studies. The large prospective comparative study EPIC used a common methodology for tracking the use of DS among the adult population of ten European countries. The results show a northsouth gradient in the use of DS, as in the United Kingdom, Denmark, Sweden and Norway, more than a third of participants used DS. (14)

The information on the frequency of use of plant-based DS is scarce and derived from specially designed and built for this purpose studies. According to the first ever European research on the type and frequency of use of plant-based DS in 6 European countries (Finland, Germany, Italy, Romania, Spain, United Kingdom) the average frequency of use $18.8 \%$, but the variations between countries are considerable. Established frequency of use of plant-based DS is highest in Italy - $22.7 \%$, followed by the United Kingdom - 19.1\%, Spain $-18.0 \%$, Germany and Romania $-17.6 \%-16.9 \%$. (15)

Most studies clarify frequency of use without explore the reasons for the widespread use of DS and plant-based DS in particular. Users' motivation of supplements use remains sustantially poorly understood. Different explanatory models are studied: dissatisfaction with conventional treatment, a desire for more personal autonomy and control over health care decisions, compatibility with personals beliefs and convictions regarding the nature of health. $(16,17,18)$ A positive association between increased use of DS and the availability of a holistic orientation to health in respondents is established. $(16,18)$ Several studies have found a positive association between a poorer health status and the increased use of DS. $(11,16,18$, 19, 20) According to Nielsen et al, the use of DS is not an expression of dissatisfaction with conventional treatment. The use of supplements is not seen as a health care alternative. (11) People use DS in conjunctions with, not instead of, conventional treatment as an expression of the desire to complement standard treatments. (12) In other studies dissatisfaction with conventional treatment has not been established as a predictor of an increased usage of DS. (16, $18,21)$ A significant proportion of consumers determine their health as very good or excellent.
$(8,22)$ In this case patients take DS to maintain their overall health and well-being. (5)

Lifestyle and related health habits are established as determinants of the use of DS. The users of DS, more than nonusers, aspire to a healthy lifestyle, including efforts to better diet, regular physical exercise, avoidance of obesity and smoking $(4,5,8,13)$. The influence of certain demographic and social factors such as age, sex, education, ethnicity, race, income is explored. (4, 8 ,) Studies indicate that higher use of DS has been associated with being female, being more educate, having a higher income, being white and being older. $(5,14)$

Regardless of the specific reason, the leading remains conviction that DS and plant-based DS are useful and harmless, as products of natural origin. The reality is that "safe" and "natural" are not synonymous. With the increasing use of DS a significant number of scientific reports, refuting the opinion for their safety appeared.

\section{THE PURPOSE OF THIS REVIEW IS:}

1. To provide a brief summary of the available literature on the risks associated with the use of different DS, especially plant-based DS .

2. To summarize the views on possible approaches to reducing these risks associated with DS use.

3. To draw the attention of the professional medical community to the need for:

- increasing healthcare professionals' knowledge about the benefits and risks associated with use of DS;

- constructing a new type of relationship between health professionals and consumers of plantbased and other DS;

- establishing effective tools for post-marketing control;

- changing the current regulatory practices;

\section{Risks associated with use of DS.}

Risks associated with use of DS and plant-based DS most often include the possibility of adverse effects and unwanted interactions between DS and drugs.

In comparison with the pharmaceutical products, most DS including plant-based DS inherent wider safety margin, but the presence of biologically active substances, most of them of unknown pharmacological activity, as well as in synthetic drugs, may cause various adverse reactions (ARs) $(23,24,25)$. 
According to Health and Diet Survey, for 2002 $4 \%$ of the users observed ARs believed to be due to the use of DS. (26) It is difficult to determine whether ARs are related to the nature of the DS or other factors, such as an improper use of the products; physiological and pathological characteristics of the body (sex, age, genetic terrain, concomitant diseases and therapies); low quality of products (incorrectly disclosed composition, the presence of drugs, heavy metals, pesticides, pathogenic microorganisms, etc.) (27) In many cases, patients have used more than one DS for a short or longer period of time. Furthermore DS often used in combination with prescribed conventional medicines and this creates an opportunity for interactions, both between DS and between DS and drugs. $(28,29)$ The possibility of interactions increases with the number of used products. A huge number of possible adverse interactions between natural products and conventional medicines are described in The Natural Medicines Comprehensive Database. (30) The greatest number of documented interactions with drugs are observed in DS containing Hypericum perforatum, magnesium, calcium, iron, Ginkgo biloba. As can be expected warfarin, ticlopidine, aspirin, insulin, digoxin and other medicines with a narrow therapeutic window have the greatest number of documented interactions with DS. (31) Although most documented interactions have no serious consequences, it is not a rule, and some interactions can have dangerous consequences. (32) For example interactions of Hypericum perforatum with a number of medications may be the cause of serious consequences. $(33,34)$ With increasing use of DS is expected to grow the number of reports that document a growing number of clinically significant interactions.

\section{Factors increasing the risk associated with the use of DS}

\section{By patients:}

Self-treatment. Significant proportion of people use DS without prescription, as a self-treatment .(35) Widespread use of these products is a matter of concern because the advertising can cause many users to abandon conventional treatment in favor of products which may not offer health benefits or seek health advice from medical untrained and unqualified persons. (36) "Self-treatment" can lead to the delay of appropriate therapies and put at risk the health of patients, especially in case of serious diseases.
SOKOLOVA K., et al.

Nondisclosure DS use to physicians. Many studies show that more than half of the US population with chronic diseases take DS alongside conventional medicines as an adjunctive therapy $(20,32,37,38)$. This is associated with increased risk of ARs and interactions. (29) This risk is even more likely due to the fact that only about $30 \%$ of patients told their doctor about DS use. $(39,40,41)$ A comparison of the data from NHIS for 2002 and 2007 notes a tendency to increase the proportion of respondents that disclosed DS use to their physicians - from 33, 4\% in 2002 to $45,4 \%$ in 2007. (42) In studies that try to clarify the reasons why patients do not disclosed DS use to their physicians the following answers are received: "It wasn't important for the doctor to know", "The doctor never asked", "It was none of the doctor's business", and „The doctor would not understand". Fewer respondents thought their doctor would disapprove of or discourage unconventional methods, and $2 \%$ thought their doctor might not continue as their provider. (21, 43) The high degree of DS use, combined with the low frequency of disclosure of this use, creating risk situations.

\section{By physicians:}

\section{Lack of adequate knowledge.}

Physicians are strongly divided in their attitude towards the use of DS. $(44,45)$ Some are absolute opponents, others have a positive attitude and believe that DS have their place in modern medical practice; use them for themselves and recommend them to their patients. $(46,47,48)$ Most recognize a lack of general knowledge regarding DS $(28,49,50)$ and this gaps of knowledge complicates patientdoctor communication. (51) Physicians do not commonly ask patients about their DS use, and patients may feel uncomfortable discussing it. According some studies, a significant proportion of physicians show interest and desire to acquire knowledge about the benefits and risks associated with the use of DS. Since registration of DS does not require evidence of their effectiveness and safety, then the scientific data of this nature are limited. Despite the long history of traditional use, many of DS have unproven effectiveness in modern scientific standards. There are no prospective, randomized clinical trials on the safety and efficacy of dietary supplement. (52) The great consumers' interest and the widespread use stimulate research activity, but there is still a scarcity of information concerning the effectiveness and safety of DS. Except that the available data are 
relatively small, often they are of unsatisfactory quality and this makes it difficult to interpret them and draw conclusions.

\section{Weakness in regulation.}

The legislative frameworks that regulate the production and marketing of DS are different in different countries, but the common is that the production of such products is not subject to the strict requirements such for the production of pharmaceuticals.

In the EU there are differences between countries and the proliferation of DS is under the control of different national laws. An effort to approximate the laws of individual countries is Directive 2002/46 / EC, which sets clear rules regarding accuracy of substantiated claims, requirements for the text in advertising and product labeling and a ban on trade in products which do not meet these requirements. A positive list of vitamins and minerals which may be incorporated in HD is introduced. The legislation with regard to the other types of DS has not yet been completed. A list of herbal ingredients allowed in the composition of DS is in development. Due to these differences and limited harmonization laws, Directive 2002/46 / EC, provide existing national rules in the regulation to be mutually recognized between Member States. (7)

Legal regulations in terms of the DS in the US are formulated in DSHEA. Unlike drugs, which must be approved by the FDA before they can be marketed, FDA does not regulate DS, and there are no pre-market safety or efficacy studies required. Under this law, the supplement company is responsible for having evidence that their products are safe and the label claims are truthful and not misleading, but they do not have to provide that evidence to the FDA before the product is marketed. FDA is responsible for post-marketing control over their safety and can take legal action against companies by using a warning or removing the products, if they are unsafe. (6)

\section{Possible approaches to solve the problem}

By patients: It is necessary to build a new consumers culture in people who use DS. They should be aware that there is no completely safe DS and it is important to create an attitude to disclose the use of DS to their doctor. The doctor should be informed and, if necessary, to assist in the choice of appropriate supplements for each patient.
By doctors: There is an obvious need to improve their knowledge in this area. It is important to be aware of current evidence-based information to answer patient questions and help them in making informed decisions adequate to their health status. This requires appropriate actions at different levels. Providing education (courses and continuing education programs) to health care professionals in this area may help to integrate DS into mainstream medical care. Regardless of ltheir personal opinion physicians should realize the need of partnership with patients. They should always ask patients about unconventional treatments discuss herbal supplement use and document this information in the medical records. (53).

Regulatory changes: Although DS are used for a long time, their regulation and legislation has many weaknesses. The current regulation does not ensure that available DS are safe. False and illegal marketing claims are common. There is a need to update the regulation of this fast-growing market and to harmonize legislation on DS. (54, 55) Changes to the regulation of DS could dramatically improve their safety and appropriate use. (56)

Herbal pharmacovigilance. The broad use and uncontrolled distribution of DS strengthen the need for monitoring tools regarding their performance and especially their safety. DS safety becomes a significant factor in public health (57) and proves a challenge for health systems and regulatory authorities at regional and global levels. WHO recognizes the growing importance of the use of DS, especially plantbased DS, and the need to develop recommendations for monitoring their safety. Although, plant based DS are not registered as medicines, WHO has assumed that the monitoring system for their safety should be part of existing national systems of pharmacovigilance (PV). WHO's recommended approach is to expand the existing systems for PV and to adapt them for successful monitoring of plant based DS. (58) PV is the science and activities related to the detection, assesment, understanding and prevention of adverse drug reactions or any possible drug related problems. Current PV systems are in line with WHO International Drug Monitoring Programme introduced in 1970. The standard method for monitoring drug safety is through the spontaneous reporting system of ARs. Underreporting of this method for $\mathrm{PV}$ is recognized as a real problem of international importance. Only 
$10 \%$ of ARs were reported through spontaneous reporting (59). Often, users do not seek professional advice in the selection and use of a specific medicinal product. A possible practice in this context is the enrollment of patients and FP in the reporting of ARs. A key point and a serious obstacle to PV are the lack of an established international classification and nomenclature of raw materials and products of plant origin. Since there are regulatory and cultural differences in the distribution and use of RIP leading to the emergence of specific regional problems, WHO encourages everyone to offer suggestions and to be an active participant in the development of guidelines (58). DS inclusion in the existing PV system will help to gather the information necessary for the elaboration of appropriate guidelines for the safe and effective use of DS (60).

\section{CONCLUSION}

The safety of DS, including plant-based DS, is essential because they are used for selfmedication, not only in the case of minor deviations, but also for serious chronic diseases. Undoubtedly, DS can be helpful when used properly and under the supervision of a specialist. The professional medical community must be knowledgeable about the safety of such products and advise their selection. Given that a significant portion of the DS is available without prescription, a professional and ethical attitude toward consumers and patients requires pharmacists and other medical professionals also to be aware of and warn about the potential risk. Successful integration of DS into existing PV systems will allow the documentation of a growing number of ARs and interactions allowing more effective risk-benefit assessment. The goal is not to create a negative attitude towards the use of DS, but to identify and prevent the possible risks in terms of their best integration in contemporary therapeutic regiments.

\section{REFERENCES}

1. Cavaliere C, Rea P, Lynch ME, Blumenthal $M$, Herbal supplement sales rise in all channels in 2009. Herbalgram, 86: 62-65, 2010.

2. European Advisory Services (EAS) (2007). The use of substances with nutritional or physiological effect other than vitamins and minerals in food supplements study undertaken for DG SANCO, European Commission:Available:http://ec.europa.eu/fo $\mathrm{od} /$ food/labellingnutrition/supplements/docu
SOKOLOVA K., et al.

ments/2007_A540169_study_other_substanc es.pdf

3. Garcia-Cazarin ML, Wambogo EA, Regan KS, Davis CD, Dietary supplement research portfolio at the NIH, 2009-2011. JNutr,144 (4): 414-8, 2014.

4. Bailey RL, Gahche JJ, Lentino CV, et al, Dietary supplement use in the United States, 2003-2006. J Nutr, 141(2): 261-266, 2011.

5. Dickinson A, Blatman J, El-Dash N, Franco JC. Consumer usage and reasons for using dietary supplement: report of series of surveys. J Am Coll Nutr,33(2):176-82, 2014.

6. FDA.US Food and Drug Administration. Regulatory Information.Dietary Supplement Health and Education Act of 1994 http://www.fda.gov/RegulatoryInformation/ Legislation/FederalFoodDrugandCosmeticA ctFDCAct/SignificantAmendmentstotheFDC Act/ucm148003.htm\#sec3

7. European Directive 2002/46 / EC https://www.fsai.ie/uploadedFiles/Dir\%2020 02.46\%20EC\%282\%29.pdf)"

8. Radimer K, Bindewald B, Hughes J, Ervin B, Swanson C, Picciano MF, Dietary supplement use by US adults: data from the National Health and Nutrition Examination Survey, 1999-2000. Am J Epidemiol, 160: 339-49, 2004.

9. Messerer M, Johansson S.-E, Wolk A, Use of dietary supplements and natural remedies increased dramatically during the 1990s. Journal of Internal Medicine, 250: 160-166, 2001.

10. Menniti-Ippolito F, Gargiulo L, Bologna E, Forcella E, Raschetti R, Use of unconventional medicine in Italy: a nationwide survey. Eur J Clin Pharmacol, 58: 6164, 2002.

11. Nielsen MW, Hansen EH, Rasmussen NK Use of natural medicines in the Danish population: a national cross-sectional survey. Ann Pharmacother, 39: 1534-1538, 2005.

12. Metcalfe A, Williams J, McChesney J, Patten, SB, Jette N, Use of complementary and alternative medicine by those with a chronic disease and the general population results of a national population based survey. BMC Complementary and alternative medicine, 10:58, 2010.

13. Rovira MA, Grau M, Castañer O, Covas MI, Schröder $\mathrm{H}$, REGICOR Investigators Dietary supplement use and health-related behaviors in a mediterranean population. $\mathrm{J}$ Nutr Educ Behav, 45(5): 386-391, 2013.

14. Skeie G, Braaten T, Hjartaker A, Lentjes M, Use of dietary supplements in the European 
SOKOLOVA K., et al.

Prospective Investigation into Cancer and Nutrition calibration study. Eur J Clin Nutr, 63: 226-238, 2009.

15. Garcia-Alvarez A, Egan B, de Klein S, et al, Usage of Plant Food Supplements across Six European Countries: Findings from the PlantLIBRA Consumer Survey. Müller M, ed. PLoS ONE, 2014;9(3):e92265. doi:10.1371/journal.pone.0092265.

16. Astin JA, Why patients use alternative medicine: results of national study. JAMA, 279(19): 1548-53,1998.

17. Testerman JK, Morton KR, Maon RA Ronan AM, Patient Motivations for Using Complementary and Alternative Medicine. Journal of Evidence-Based Complementary \& Alternative Medicine, 9(2): 81-92, 2004.

18. Bishop FL, Yardley L, Lewith GT, A systematic review of believes involved in the use of complementary and alternative medicine. J Health Psychol, 12(6): 851-867, 2007.

19. Satia-AboutaJ, Kristal AR, Patterson RE, Littman AJ, Stratton KL, White E, Dietary supplement use and medical conditions: the VITAL study. Am J Prev Med,24(1): 43-51, 2003.

20. Miller MF, Bellizzi KM, Sufian M, Ambs AH, Goldstein MS, Ballard-Barbash R, Dietary supplement use in individuals living with cancer and other chronic conditions: a population-based study. J Am Diet Assoc, 108(3): 483-94, 2008.

21. Eisenberg DM, Kessler RC, Van Rompay MI, Kaptchuk TJ, Wilkey SA, Appel S, Davis RB, Perceptions about complementary therapies relative to conventional therapies among adults who use both: results from a national survey. Ann Intern Med, 135(5): 344-51, 2001.

22. Ervin RB, Wright JD, Kennedy-Stephenson $\mathrm{J}$, Use of dietary supplements in the United States, 1988-94. National Center for Health Statistics. Vital Health Stat, 11(244), 1999.

23. Palmer ME, Haller C, McKinney PE, KleinSchwartz W, Tschirgi A, Smolinske SC, Woolf A, Sprague BM, Ko R, Everson G, Nelson LS, Dodd-Butera T, Bartlett WD, Landzberg BR, Adverse events associated with dietary supplements: an observational study. Lancet, 361 (9352): 101-6, 2003.

24. Pittler MH, Ernst E, Review Systematic review: hepatotoxic events associated with herbal medicinal products. Aliment Pharmacol Ther, 18(5): 451-71, 2003.

25. Haller C, Kearney T, Bent S, Ko R, Benowitz N, Olson, K, Dietary supplement adverse events: report of a one-year poison center surveillance project. J Med Toxicol, 4(2): 84-92, 2008.

26. Timbo BB, Ross MP, McCarthy PV, Lin CT,

http://www.ncbi.nlm.nih.gov/pubmed/17 126626Dietary supplements in a national survey: Prevalence of use and reports of adverse events. J Am Diet Assoc, 106(12): 1966- 74, 2006.

27. Newmaster SG, Grguric M, Shanmughanandhan D, Ramalingam $\mathrm{S}$ and Ragupathy S, DNA barcoding detects contamination and substitution in North American herbal products. BMC Medicine, $11: 222,213$

28. Izzo AA, Herb-drug interactions: an overview of the clinical evidence. Fundam Clin Pharmacol, 19: 1-16, 2005.

29. Izzo AA, Ernst E, Interactions between herbal medicines and prescribed drugs: an updated systematic review. Drugs, 69: 1777-1798, 2009.

30. The Natural Medicines Comprehensive Database:http://naturaldatabase.therapeuticre search.com/Content.aspx?cs=\&s=ND\&page $=$ edprinciples $\& \mathrm{xsl}=$ generic

31. Tsai H.-H, Lin H.-W, Pickard S.A, Tsai H.Y, Mahady G.B, Evaluation of documented drug interactions and contraindications associated with herbs and dietary supplements: a systematic literature review. Int J Clin Pract, 66(11): 1056-78, 2012.

32. Posadzki P, Watson LK, Alotaibi A, Ernst E, Prevalence of use of complementary and alternative medicine (CAM) by patients/consumers in the UK: systematic review of surveys. Clin Med, 13(2): 126-31, 2013.

33. Hu Z, Yang X, Ho PCL, Chan SY, Heng PWS, et al, Herb-drug interactions: a literature review.Drugs,65:1239-1282, 2005.

34. Henderson L, Yue QY, Bergquist C, Gerden B, Arlett P, St John's wort (Hypericum perforatum): drug interactions and clinical outcomes. British Journal of Clinical Pharmacology, 54(4): 349-356,2002.

35. Eichhorn T, Greten H J, and Efferth T, Selfmedication with nutritional supplements and herbal over-the-counter products. Nat. Prod. Bioprospect, 1: 62-70, 2011.

36. Denham BE, Dietary supplementsregulatory issues and implications for public health. JAMA, 306(4): 428-9,2011.

37. Blendon RJ, DesRoches CM, Benson JM, Brodie M, Altman DE, Americans' views on 
the use and regulation of dietary supplements. Arch Intern Med, 161(6): 80510, 2001.

38. Yeh GY, Eisenberg DM, Davis RB, Phillips RS, Use of complementary and alternative medicine among persons with diabetes mellitus: results of a national survey. Am J Public Health., 92(10):1648-52, 2002.

39. Mehta DH, Gardiner PM, Phillips RS, McCarthy EP, Herbal and dietary supplement disclosure to health care providers by individuals with chronic conditions. J Altern Complement Med, 14 (10): 1263-9, 2008.

40. Kennedy J, Herb and supplement use in the US adult population. ClinTher, 27(11): 1847-58, 2005.

41. Kennedy J, Wang CC, Wu CH. Patient disclosure about herb and supplement use among adults in the US. Evid Based Complement Alternat Med,5:451-456, 2008.

42. Wu CH, Wang CC, Kennedy J, Changes in herb and dietary supplement use in the $\mathrm{U}>\mathrm{S}>$ adult population: a comparison of the 2002 and 2007 National Health Interiew Surveys. Clin Ther, 33(11):1749-1758, 2011.)

43. Robinson A, McGrail MR, Disclosure of CAM use to medical practioners: a review of qualitative and quantitative studies. Complement Ther Med,12(2-3): 90-98, 2004.

44. Milden SP, Stokols D, Physicians' attitudes and practices regarding omplementary and alternative medicine. Behav Med, 30:73-82, 2004

45. Barrett B, Complementary and alternative medicine: what's it all about?. WMJ, 100(7): 20-26, 2001.

46. Astin JA, Marie A, Pelletier KR, Hansen E, Haskell WL, A review of the incorporation of complementary and alternative medicine by mainstream physicians. Arch Intern Med, 158(21): 2303-10, 1998.

47. Joos S, Musselman B, Miksch A, Rosemman $\mathrm{T}$, Szecsenyi J, The role of complementary and alternative medicine (CAM) in Germany - A focus group study of GPs. BMC Health Serv Res, 8: 127, 2008.

48. Dhanani S, Yoh E, Harada N, Percy L, Makinodanl T, Assessing clinician's knowledge on herbal medicine. Fed Pract, 22(11): 69-75, 84, 2005.
49. Geller SE, Studee L, Chandra G, Knowledge, attitudes, and behaviors of healthcare providers for botanical and dietary supplement use for postmenopausal health. Menopause, 12(1): 49-55, 2005.

50. Kemper KJ, Amata-Kynvi A, Dvorkin L, Whelan JS, Woolf A, Samuels RC, Hibberd $\mathrm{P}$, Herbs and other dietary supplements: healthcare professionals' knowledge, attitudes, and practices. Altern Ther Health Med, 9(3): 42-9, 2003.

51. Bouwmeester CJ, Surveying physicians' attitudes about herbal supplements, resources, and pharmacy consultations. $J$ Pharm Technol, 21: 247-53, 2005.

52. Sadovsky R, Collins N, Tighe AP, Brunton SA, Safeer R, Patient use of dietary supplements: a clinician's perspective. Curr Med Res \& Opin, 24(4)4: 1209-1216, 2008.

53. Haller CA, We should always ask our patients about unconventional treatments. West J Med, 175(3): 164, 2001

54. Lewis JD, Strom BL, Balancing safety of dietary supplement with the free market. Ann Intern Med, 136: 616-8, 2002; Marcus DM, Grollman AP, Botanilal medicines-the need for new regulations. $N$ Engl J Med, 347: 2073-6, 2002.

55. Marcus DM, Grollman AP, Botanilal medicines-the need for new regulations. $N$ Engl J Med, 347: 2073-6, 2002.

56. Bent $S$, Herbal medicine in the United States: review of the efficacy, safety and regulation. J Gen Intern Med, 23(6): 854-9, 2008

57. WHO guidelines on safety monitoring of herbal medicines in pharmacovigilance systems. World Health Organization. Geneva, 2004.

58. Sandeep Sh., Kumar SD, Sriwastava NK, Sharma IP, Pharmacovigylance of herbal medecines: Current state and future directions. Pharmacogn Mag, 7 (25): 69-73, 2011.

59. Rishma W, Heather Boon ND, Welsh S. Adverse Event Reporting for Herbal Medicines: A Result of Market Forces. Healthcare policy, 4(4): 77-90, 2009.

60. Shaw D., Graeme L., Duez P., Williamson E. Chan K, Pharmacovigilance of herbal medecine. Journal ot Ethnopharmacology, 140: 513-518, 2012 